\title{
Effects of different parameters on the removal of atrazine in a water environment by Aspergillus oryzae biosorption
}

\author{
Jian Lu, ${ }^{\dagger}$ Ruirui Li, ${ }^{\dagger}$ Yuansen Chang, Yang Zhang, Nan Zhang, Liming Tao and Wenping Xu* \\ Shanghai Key Laboratory of Chemical Biology, School of Pharmacy, East China University of Science and Technology, Shanghai 200237, China \\ (Received July 16, 2021; Accepted March 3, 2021)
}

S Supplementary material

\begin{abstract}
Atrazine is the most extensively used herbicide in the agricultural and forestry sectors. Nevertheless, along with the increasing usage amount of Atrazine, its harm exposed gradually, the main problem is its residues in the environment. Microbial adsorption may effectively reduce the pollution caused by atrazine residue in the environment. In this study, a strain of fungi with the function of adsorbing atrazine was selected using microbial screening technology. According to its phenotypic characteristics and 18S rDNA gene sequencing, this strain was of the species genus Aspergillus and was named ECUST-TXZC2018. By studying the dynamic adsorption effect of this strain on atrazine, we found that this strain adsorbed atrazine after $36 \mathrm{hr}$ at $\mathrm{pH}=5-7$, and $20-30^{\circ} \mathrm{C}$ with more than $70 \%$ adsorption. These results demonstrated that ECUST-TXZC2018 had potential application ability to control atrazine residue pollution through the biosorption function.
\end{abstract}

Keywords: herbicide residue, atrazine, aspergillus, biosorption, removal.

\section{Introduction}

Atrazine (AT), a chlorinated triazine herbicide, has been widely used in many countries around the world due to its low cost and good herbicidal effect. ${ }^{1)}$ During application, $20-70 \%$ of the pesticide enters the soil, and AT is characterized by a stable structure, long half-life (8-52 weeks), poor biodegradation, and extremely slow mineralization by microorganisms. ${ }^{2)} \mathrm{AT}$ is a colorless crystal with a boiling point of $200^{\circ} \mathrm{C}$ and an acidity coefficient $\left(\mathrm{p} K_{\mathrm{a}}\right)$ of 1.68 ; is moderately soluble in water, with a solubility of $33.0 \mathrm{mg} \mathrm{L}^{-1}$ at $22^{\circ} \mathrm{C}$; and has a low soil adsorption coefficient $\left(K_{\mathrm{oc}}\right)$ of $100 \mathrm{~cm}^{3} \mathrm{~g}^{-1}$ and an octanol-water partition coefficient $\left(\log K_{\text {ow }}\right)$ of $2.75 .{ }^{3)}$ Due to precipitation, leaching, and surface runoff, atrazine and its degradation products in soil may migrate into the water environment, causing surface

\footnotetext{
* To whom correspondence should be addressed.

E-mail:xuwp@ecust.edu.cn

† These authors contributed equally to this work.

Published online May 7, 2021
}

(c) BY-NC-ND $\odot$ Pesticide Science Society of Japan 2021. This is an open access article distributed under the Creative Commons Attribution-NonCommercial-NoDerivatives 4.0 International (CC BY-NC-ND 4.0) License (https://creativecommons.org/licenses/by-nc-nd/4.0/) water and groundwater pollution. ${ }^{4)}$ The United States has established $3 \mu \mathrm{g} \mathrm{L} \mathrm{L}^{-1}$ as the maximum contaminant level for atrazine in drinking-water supplies. ${ }^{5)}$

Several studies have demonstrated the toxic effects atrazine can have on the developmental processes of the natural environment, human beings, animals, and plants. ${ }^{6}$ AT exposure can cause a reduction in the levels of vitellogenin $(\mathrm{Vg})$ in the estuarine crab Neohelice granulata, slowing and inhibiting ovarian growth. ${ }^{7)}$ Exposure to low doses of atrazine affects the sperm parameters in mice and, therefore, may plausibly reduce the reproductive capacity of wild rodent species. ${ }^{8)}$ AT may also have potential carcinogenic effects in the human body, and there is a risk of transmission and amplification along the food chain.

The current methods for atrazine management in sewage are mainly physicochemical. These methods are often expensive or technically demanding and are sometimes accompanied by secondary pollution. Although some new technologies are currently undergoing research, such as using ion exchange resins, polymers, and nano-based adsorbents, there is still a long way to go before these methods will be suitable for practical application. ${ }^{9-11)}$ In recent years, some fungi, bacteria, and algae have been used to remove metal ions, dyes, and pesticides. ${ }^{12)}$ Relative to physicochemical methods, this method of removal has an improved cost-performance ratio, regenerative capacity, higher adsorption efficiency, and no toxic side effects. ${ }^{13)}$ Microbial re- 
A

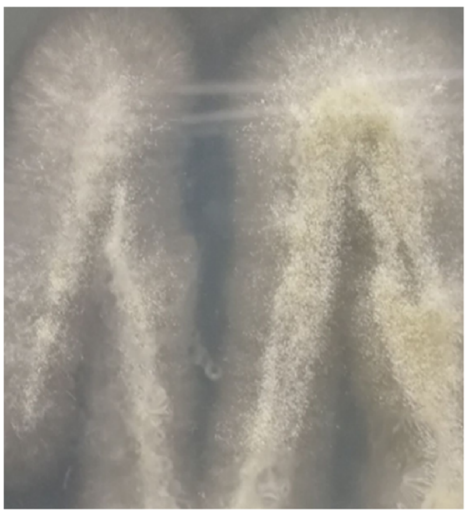

B

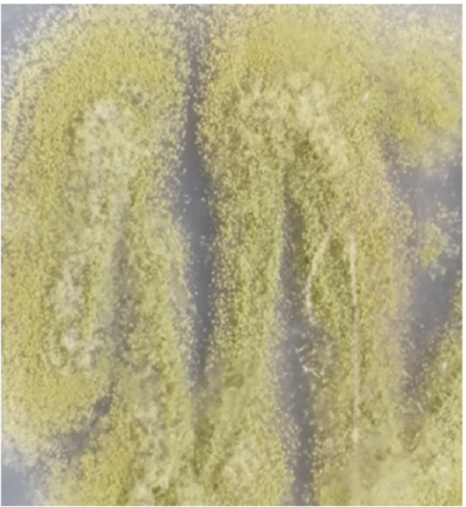

Fig. 1. Colony growth characteristics of strain ECUST-TXZC2018: (A) early growth; (B) late growth.

moval of pesticides is mainly divided into biodegradation and biosorption, and biodegradation is the focus of the microbial treatment of pesticide pollution. ${ }^{14)}$ Biodegradation of atrazine by microorganisms is a multistep process leading to the formation of hydroxy, dechlorinated, or dealkylated byproducts like hydroxyatrazine, deethyl, or deisopropyl atrazine, which can be further transformed into ammeline, ammelide or cyanuric acid and completely mineralized. ${ }^{15)}$ In spite of the research on the microbial treatment of pesticide pollution being mainly focused on degradation, in recent years, there have also been many studies on the treatment of pesticide pollution using biosorption. ${ }^{16)}$ Microbes have been used to adsorb atrazine, and 14 strains of bacteria that adsorb atrazine have been found. ${ }^{17}$

The purpose of this study was to screen out microorganisms with the functionality of adsorbing atrazine from the soil using an enrichment technique and to identify and classify the selected strains according to their physicochemical properties and molecular biological characterization. Then the adsorption capacity was further analyzed, and the effects of different factors on the adsorption of atrazine and a preliminary study of the adsorption mechanism were explored.

\section{Materials and methods}

\section{Materials and methods}

All experimental work was carried out using non-contaminating glassware. The glassware was washed with tap water three times, then dried in a hot -air oven at $100^{\circ} \mathrm{C}$ for $6 \mathrm{hr}$ so as to prevent any persistent contamination.

The chemicals and reagents used in the study were of analytical reagent (AR) grade and were purchased from Shanghai Titan Technology Co., Ltd. Atrazine ( $\geq 98 \%$ ), chlorpyrifos ( $\geq 98 \%$ ) and avermectin $(\geq 95 \%)$ were provided by Shanghai Pesticide Research Institute Co., Ltd., and a stock solution $\left(1 \mathrm{gL}^{-1}\right)$ was prepared in pure methanol and diluted for preparation of the working solutions.

\section{Isolation and identification of adsorbent microbes}

Soil $(10 \mathrm{~g})$ from an area contaminated with atrazine was enriched and cultured in $90 \mathrm{~mL}$ of liquid beef extract glucose me- dium (BGM) containing $200 \mathrm{mg} \mathrm{L}^{-1}$ atrazine. The BGM consisted of $\mathrm{NaCl}(10 \mathrm{~g})$, glucose $(10 \mathrm{~g})$, beef extract $(5 \mathrm{~g})$ and water (1 L). After $48 \mathrm{hr}$, the supernatant was diluted by $10^{-6}, 10^{-7}$, and $10^{-8}$, and $0.1 \mathrm{~mL}$ of each sample was applied to the BGM containing atrazine. Each gradient was technically triplicated and plates were incubated at $25^{\circ} \mathrm{C}$ for 3 days. After the microbes were grown, colonies with different shapes, sizes, colors, and other identifiable characteristics were picked and purified by streaking onto a plate until single unique colonies corresponding to a purified strain were obtained. The purified strain was inoculated on a beveled surface of a BGM and stored in a refrigerator at $4^{\circ} \mathrm{C}$ until further use. The isolated strains were inoculated into the fermentation medium containing atrazine $\left(200 \mathrm{mg} \mathrm{L}^{-1}\right)$, and the samples were cultured at $30 \pm 2^{\circ} \mathrm{C}$ and centrifuged at $4 \mathrm{~g}$ for 3-4 days. The fermentation supernatant was extracted with ethyl acetate, and the amount of atrazine in the fermentation broth was determined using high-performance liquid chromatography (HPLC).

The functional strain was cultured in $\mathrm{BGM}$ at $28^{\circ} \mathrm{C}$ for $5-7$ days, and the growth status of the strain was observed. In addition, the physiological and biochemical indicators of the functional strain were determined, including source utilization (the carbon sources used were D-(+)-Glucose, D(+)-Mannose, L-(+)Arabinose, L-Inositol, fructose, sucrose, maltose, and galactose), starch hydrolysis ability, whether it produced a gelatin hydrolytic enzyme and hydrogen sulfide, cellulose degradation ability, and the hydrolysis of tyrosine.

The strain was inoculated into a liquid BGM and cultured at $30^{\circ} \mathrm{C}$ for $72 \mathrm{hr}$, and then the mycelia were collected by centrifugation. Total DNA was extracted using the Ezup column fungal genomic DNA extraction kit (Sangon Biotech (Shanghai) Co., Ltd., Shanghai, China). The small ribosomal subunit (18S rDNA) was amplified via polymerase chain reaction (PCR) using TR1 5'-GTT TCT AGG ACCGCCGTA-3' and TR2 5' -CTCAAA CTT CCA TCG ACT TG-3' as primers. PCR amplification was conducted using the Thermal Cycler Gene Amp PCR System 2720 (Applied Biosystems, USA) in a $25 \mu \mathrm{L}$ volume containing a $2.5 \mu \mathrm{L} 10 \times$ mix and $0.5 \mu \mathrm{L}$ each of $10 \mu \mathrm{M}$ primer stock, $1 \mu \mathrm{L}$ of template genomic DNA, and $20.5 \mu \mathrm{L}$ of $\mathrm{ddH}_{2} \mathrm{O}$. The PCR reac- 


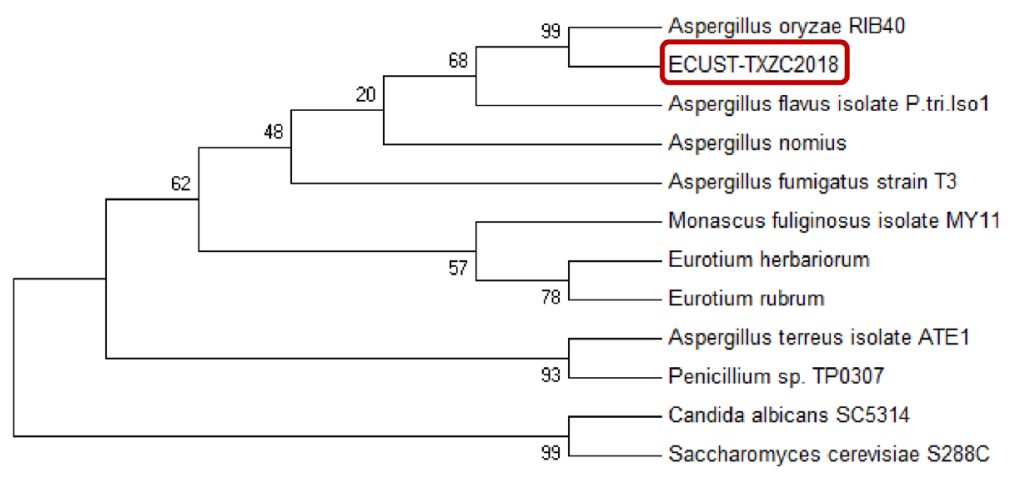

Fig. 2. Phylogenetic tree of strain ECUST-TXZC2018.

tion involved the following steps: pre-denaturation at $95^{\circ} \mathrm{C}$ for $4 \mathrm{~min}$; 30 cycles of denaturation at $94^{\circ} \mathrm{C}$ for $45 \mathrm{~s}$, annealing at $55^{\circ} \mathrm{C}$ for $45 \mathrm{~s}$, and extension at $72^{\circ} \mathrm{C}$ for $1 \mathrm{~min}$; and a final extension at $72^{\circ} \mathrm{C}$ for $4 \mathrm{~min}$. Following amplification, the PCR products were verified by electrophoresis on a $1 \%(\mathrm{w} / \mathrm{v})$ agarose gel followed by gel purification and were sequenced by Sangon Biotech (Shanghai) Co., Ltd.

The sequence was stored in GenBank and analyzed using basic local alignment search tool (BLAST). The phylogenetic tree was constructed with MEGA5.0 software using the neighbor-joining method.

\section{Batch experiments}

Batch experiments were conducted to assess the effects of various parameters, such as contact time, temperature, $\mathrm{pH}$, and initial atrazine concentration, on the adsorption removal of atrazine. The influence of the initial atrazine concentration (12.5, $25,50,100$, or $\left.200 \mathrm{mg} \mathrm{L}^{-1}\right)$, contact time $(12,24,36,48,64,84$, or $96 \mathrm{hr}), \mathrm{pH}(1,3,5,7$, or 9$)$, temperature $\left(15,20,25,30\right.$, or $\left.35^{\circ} \mathrm{C}\right)$, and $\mathrm{NaCl}$ concentration $\left(5,10,20,40,80\right.$, or $\left.120 \mathrm{gL}^{-1}\right)$ was evaluated. The strain was expanded and cultured in fermentation medium at $30^{\circ} \mathrm{C}$ and centrifuged at $4 \mathrm{~g}$ for $6 \mathrm{hr}$, then centrifuged at $955 \mathrm{~g}$ for $10 \mathrm{~min}$. The obtained pure strain was washed two to three times with sterile water/dilute nitric acid, filtered, weighed, and prepared as a concentrated microbe solution for use. The prepared concentrated microbial solution was inoculated into

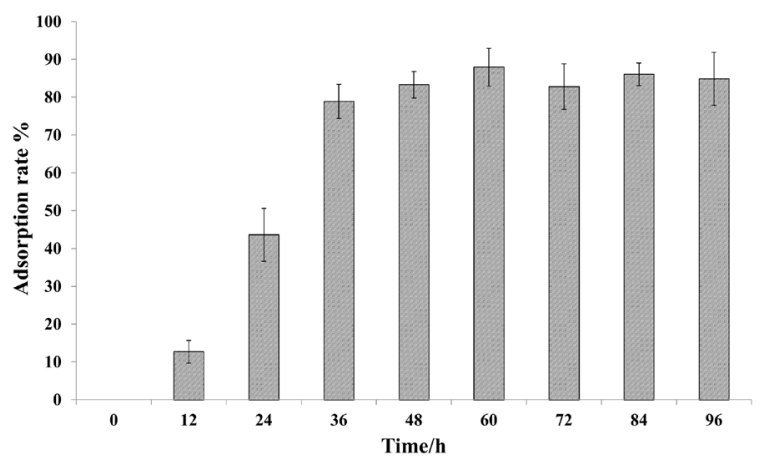

Fig. 3. The effect of contact time on the adsorption of atrazine by ECUST-TXZ2018. one of the above-indicated atrazine-containing beef extract glucose media at a ratio of $5 \%(\mathrm{v} / \mathrm{v}), 30 \pm 2^{\circ} \mathrm{C}$, and $4 \mathrm{~g}$ for $72 \mathrm{hr}$ before taking a $2 \mathrm{~mL}$ aliquot for analysis.

\section{Exploration of the biosorption mechanism}

Different methods were used to study the biosorption mechanism. A Fourier-transform infrared (FTIR) spectrometer was used to explore changes in the various functional groups on the surface of the mycelia before and after the adsorption of atrazine, while a scanning electron microscope (SEM) was used to observe the surface morphology and structural changes in the mycelia before and after atrazine adsorption.

The mycelia before and after adsorption were collected by filtration and washed with deionized water. After being dried in a freeze-dryer and combined with $\mathrm{KBr}$ powder, the mixture was pressed into slices and analyzed via FTIR spectroscopy (6700, Nicolet, USA). IR spectra were recorded in the range of $400-4000 \mathrm{~cm}^{-1}$. The mycelia were coated with gold and observed using an SEM (S-3400N, Hitachi, Japan).

\section{Residual atrazine analysis}

In this study, atrazine was extracted from the supernatant by using ethyl acetate. ${ }^{18)}$ HPLC analyses were performed using an Agilent 1200 (USA) equipped with an Agilent Eclipse Plus C18 column (Thermo Fisher Scientific, USA, $4.6 \mathrm{~mm} \times 150 \mathrm{~mm}$ ).

Table 1. Physiological and biochemical characteristics of ECUSTTXZC2018

\begin{tabular}{lclc}
\hline Carbon utilization & Result & $\begin{array}{c}\text { Physiological and } \\
\text { biochemical characteristics }\end{array}$ & Result \\
\hline D-(+)-Glucose & + & Starch hydrolysis & - \\
D(+)-Mannose & + & Gelatin hydrolytic & + \\
L-(+)-Arabinose & + & Hydrogen sulfide & + \\
L-Inositol & + & Cellulose degradation & - \\
Fructose & + & Gelatin hydrolytic & - \\
Sucrose & + & & \\
Maltose & + & & \\
Galactose & + & & \\
\hline
\end{tabular}

“+" means using or producing; "-" means not using or not producing. 


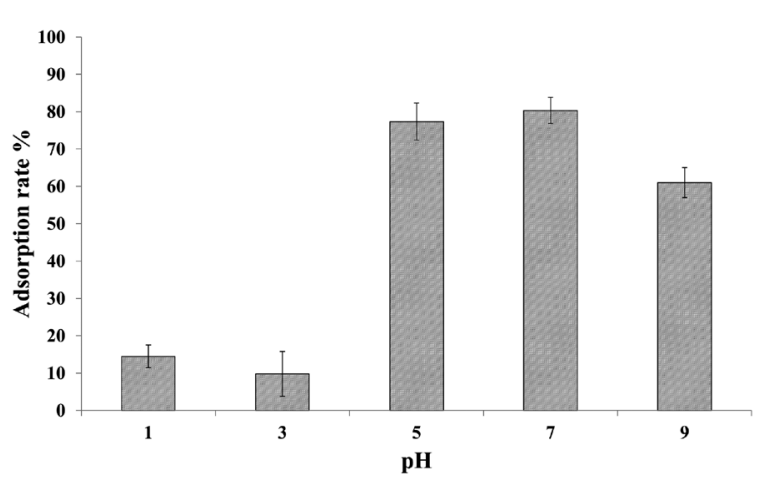

Fig. 4. The effect of $\mathrm{pH}$ on the adsorption of atrazine by ECUSTTXZ2018.

Methanol/water $(70: 30(\mathrm{v} / \mathrm{v}))$ was applied as the mobile phase at a flow rate of $1 \mathrm{~mL} / \mathrm{min}$ using an absorbance wave length of $225 \mathrm{~nm}$. The adsorption rate was calculated as follows:

$$
\begin{gathered}
\text { Adsorption rate }(\%)=\frac{\left(c_{0}-c_{t}\right)}{c_{t}} \times 100 \% \\
\text { Adsorption amount }\left(\mathrm{mgg}^{-1}\right)=\frac{\left(c_{0}-c_{t}\right) \mathrm{V}}{\mathrm{m}}
\end{gathered}
$$

in which $C_{0}$ represents the initial concentration, $C_{t}$ represents the concentration of atrazine in the solution at time $t, \mathrm{~V}$ denotes the volume of the solution $(\mathrm{L})$, and $\mathrm{m}(\mathrm{g})$ denotes the weight of the strain.

\section{Results and discussion}

\section{Isolation and identification of adsorbent microbes}

The isolated strain was cultured in BGM. The colony morphological characteristics were as shown in Fig. 1: in the early growth stage (A), the colony texture was loose and white or light yellow; in the late growth stage (B), the colony became brown to light green-brown.

The physiological and biochemical characteristics of the strain are shown in Table 1 . The results showed that the strain could be used for several carbon sources determined in this experiment

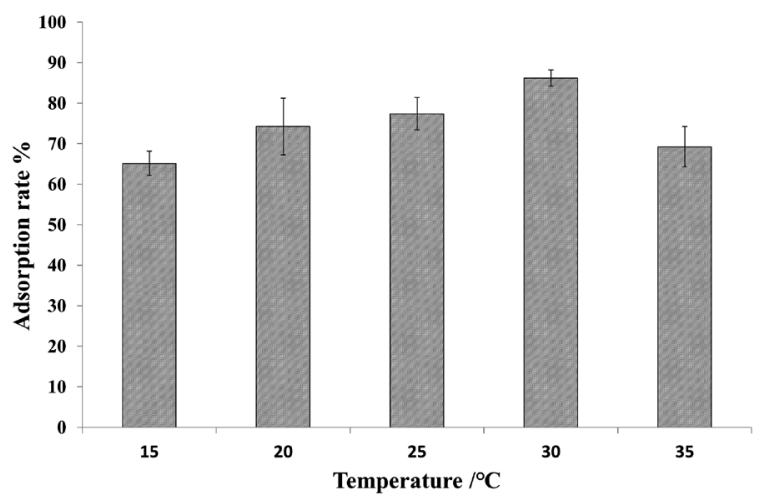

Fig. 5. The effect of temperature on the adsorption of atrazine by ECUST-TXZ2018. and could produce a gelatin hydrolytic enzyme and hydrogen sulfide. However, the strain did not have the ability to hydrolyze starch or to degrade cellulose and tyrosine.

The $18 \mathrm{~S}$ rDNA sequence of the strain was obtained via PCR to give an amplification product of $1287 \mathrm{bp}$. The $18 \mathrm{~S} \mathrm{rDNA}$ sequence was subjected to a BLAST homology comparison and evolutionary analysis in NCBI. The results show that the 18S rDNA sequence of ECUST-TXZC2018 shares 99\% homology with Aspergillus oryzae RIB40 (Fig. 2), and based on this and the results of physiological and biochemical tests and morphological structure observation, the strain was identified as a species of Aspergillus oryzae. Hence, we named the strain Aspergillus oryzae ECUST-TXZC2018. The sequence was deposited in GenBank with the accession number MH782055.

2. Effect of contact time on atrazine adsorption by ECUSTTXZC2018

To determine the dynamic adsorption equilibrium time, atrazine was adsorbed to establish the contact time, corresponding to an adsorption-rate equation. Figure 3 shows the dynamic adsorption process of strain living cells with $200 \mathrm{mg} \mathrm{L}^{-1}$ atrazine. The AT was quickly removed in the first $12-36 \mathrm{hr}$, and the adsorption rate reached 77.5\%. During this period, ECUST-TXZC2018 rapidly proliferated, providing a large number of sites for the adsorption of atrazine, so the adsorption rate was faster during this period. The adsorption rate slowed down in the $36-60 \mathrm{hr}$ period. During this period, the density of the rapidly propagating ECUST-TXZC2018 became saturated after the first $36 \mathrm{hr}$, without further provision of adsorption sites, leading to the adsorption rate slowing down until the adsorption equilibrium was reached. At $60 \mathrm{hr}$, the adsorption equilibrium was basically reached, and the adsorption rate was $85.9 \%$.

\section{Effect of pH on atrazine adsorption by ECUST-TXZC2018}

A very important influencing factor in the biosorption process is the $\mathrm{pH}$ of the solution, which can affect the composition of the colony surface groups to a large degree, thereby causing changes to the colony adsorption sites. At the same time, the change in $\mathrm{pH}$ will also cause changes in the growth state of the colony, which in turn affect the adsorption process. As shown in Fig. 4, under relatively acidic $\mathrm{pH}$ conditions $(\mathrm{pH}=1-3)$, the adsorption efficiency of the strain for atrazine is extremely low, but under slightly acidic $(\mathrm{pH}=5)$ and slightly alkaline $(\mathrm{pH}=9)$ conditions, the adsorption efficiency can be more than $60 \%$, indicating that extreme $\mathrm{pH}$ conditions have a greater impact on the adsorption of atrazine; this is mainly related to the growth state of the microbes in extreme cases. The highest adsorption efficiency occurs at $\mathrm{pH}=7$, which is the optimal $\mathrm{pH}$ for the adsorption of atrazine by the strain.

Under higher $\mathrm{pH}$ conditions, atrazine adsorption decreases. This may be due to the large number of hydroxide ions leading to the reduced adsorption capacity of the strain. ${ }^{19)}$ Electrostatic interaction exists between the charged surface of adsorbents and the charged parts of adsorbates in aqueous solutions. ${ }^{20)}$ Due to 


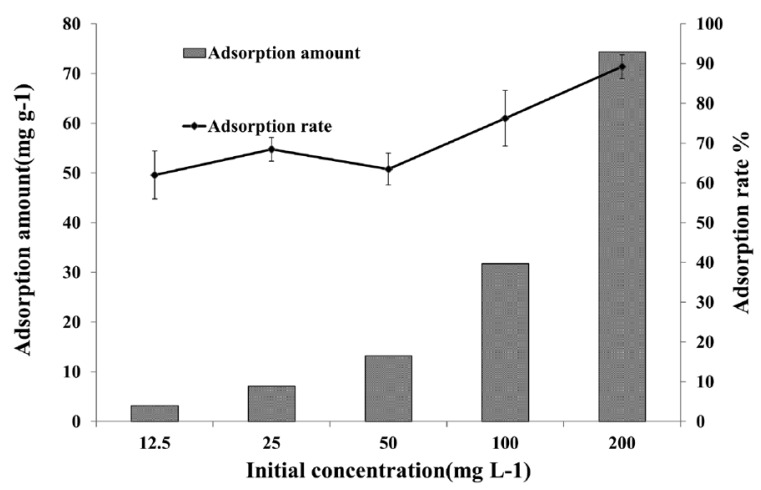

Fig. 6. The effect of the initial concentration on the adsorption of atrazine by ECUST-TXZ2018.

the presence of a large number of hydroxide ions, the number of negatively charged ions on the surface of the strain may increase, while atrazine is negative (the pka for atrazine is 1.68), thus reducing the interaction between the strain and $\mathrm{AT}^{21}{ }^{21}$ Other possible causes for such observations include pesticideadsorbent interactions due to hydrogen bonding and hydrophobic-hydrophobic interaction mechanisms. ${ }^{22)}$ In this study, with the change in $\mathrm{pH}$ value from 7 to 9 , the atrazine release rate decreased further to $20 \%$. These results are indicative of the ability of ECUST-TXZC2018 to respond differently in different $\mathrm{pH}$ solutions.

4. Effect of temperature on atrazine adsorption by ECUSTTXZC2018

Temperature is another important monitoring parameter influencing the adsorption behavior of atrazine. ${ }^{23)}$ As shown in Fig. 5, an effect of different temperatures on the adsorption of atrazine by live cells of the ECUST-TXZC2018 strain was observed for the initial concentration of $200 \mathrm{mg} \mathrm{L}^{-1}$ atrazine. As the temperature increases, the adsorption rate gradually increases. However, after reaching $30^{\circ} \mathrm{C}$, as the temperature rises, the adsorption rate decreases again. This indicates that the adsorption process is an exothermic process. The highest rate for the adsorption of atrazine $(78.2 \%)$ by ECUST-TXZC 2018 was at $30^{\circ} \mathrm{C}$; that is, $30^{\circ} \mathrm{C}$ is

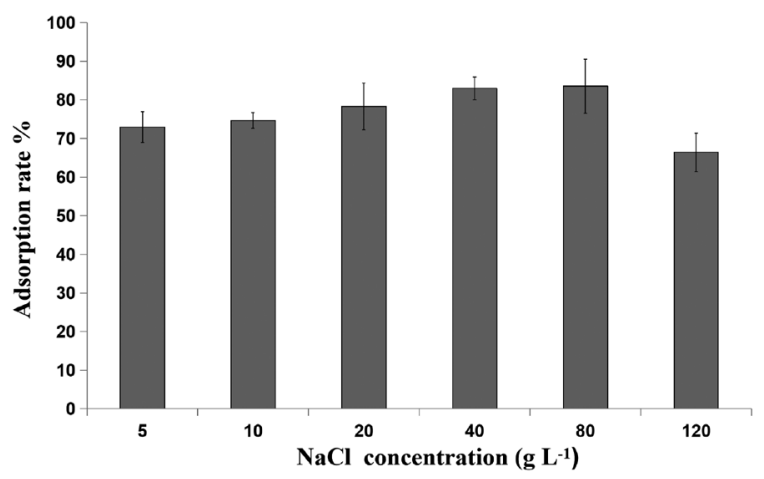

Fig. 7. The effect of $\mathrm{NaCl}$ concentration on the adsorption of atrazine by ECUST-TXZC2018.

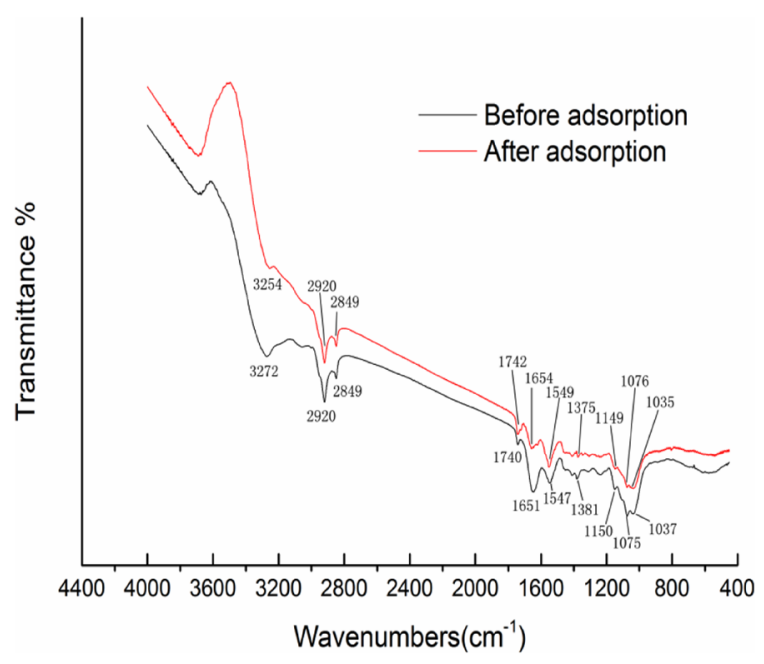

Fig. 8. FTIR spectra of the strain ECUST-TXZ2018 before and after the adsorption of atrazine.

the optimal adsorption temperature of the strain, and the adsorption rates for atrazine at $15^{\circ} \mathrm{C}$ and $35^{\circ} \mathrm{C}$ were lower. Maintenance at more than $50 \%$ indicates that the strain has potentially good application in the natural environment.

Andleeb studied the effect of soil on the adsorption of atrazine at $30^{\circ} \mathrm{C} .^{24)}$ Those results showed that with the increase in temperature, the adsorption of atrazine by the fungi decreased. This adsorption is an exothermic process, and the same trend was observed in this study. Bell and Tsezos studied the effect of using activated sludge and Rhizopus as adsorbents for the biosorption of lindane, diazinon, and malathion at temperatures of 5 and $20^{\circ} \mathrm{C}$ and observed the same trend. $\left.{ }^{25}\right)$

5. Effect of the initial concentration on atrazine adsorption by ECUST-TXZC2018

The effect of the initial atrazine concentration on the adsorption rate and capacity is illustrated in Fig. 6. The atrazine adsorption capacity increases as the initial concentration increases. However, the adsorption rate was only $60-70 \%$ at a lower initial concentration (12.5-50 $\left.\mathrm{mg} \mathrm{L}^{-1}\right)$, and it was not fully adsorbed. At an initial concentration of $200 \mathrm{mg} \mathrm{L}^{-1}$, the adsorption rate reached $89.2 \%$. This indicates that ECUST-TXZC2018 has better adsorption of atrazine at high initial concentrations. This may be because ECUST-TXZC2018 is affected by the concentration of atrazine in solution, which causes the surface morphology of ECUST-TXZC2018 or the osmotic pressure inside and outside the cell membrane to change, thus affecting the adsorption of atrazine. Subsequent supplemental test results showed that the strain still had an adsorption rate of $88.6 \%$ at $6000 \mathrm{mg} \mathrm{L}^{-1}$, which is consistent with the experimental results of Raj Kumar Pathak. ${ }^{26)}$ However, ECUST-TXZC2018 has better adsorption capacity than shown in the experimental results of Raj Kumar Pathak, etc. 


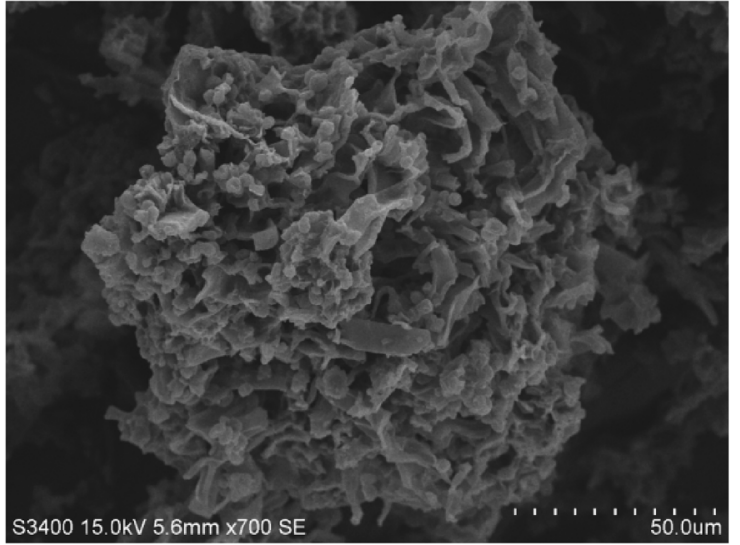

A

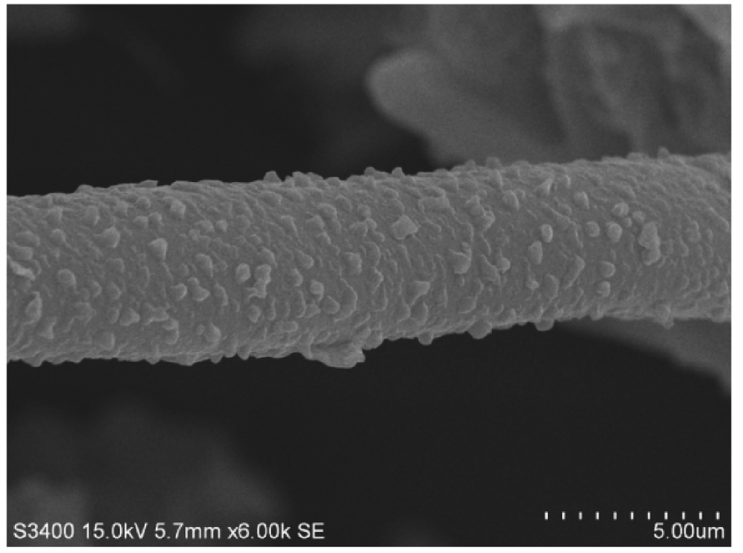

C

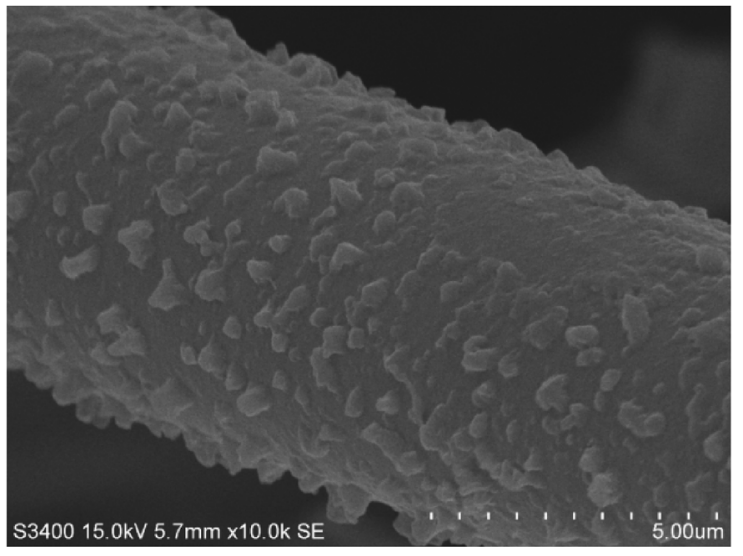

$\mathbf{E}$

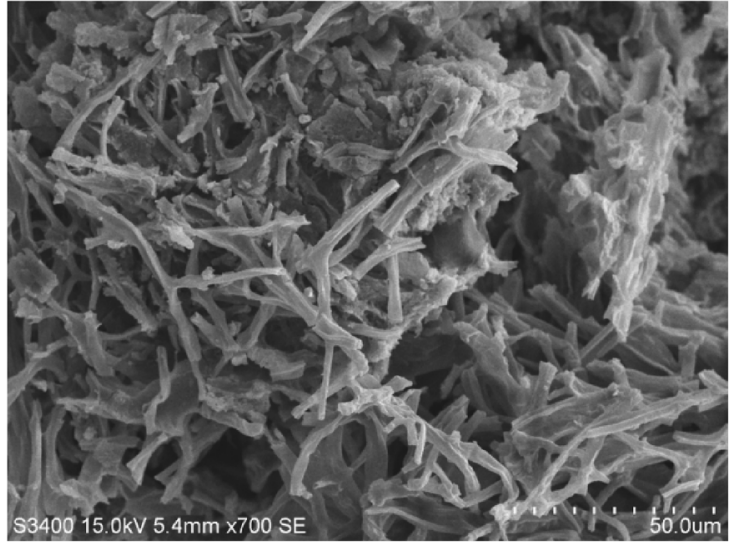

B

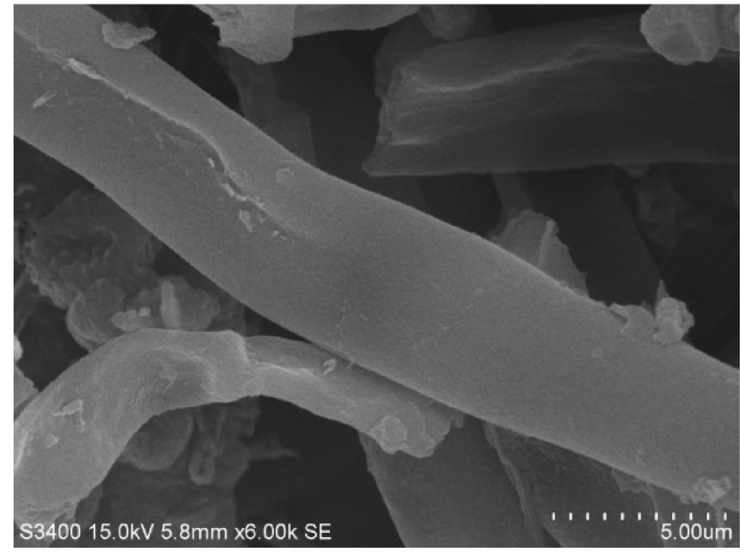

D

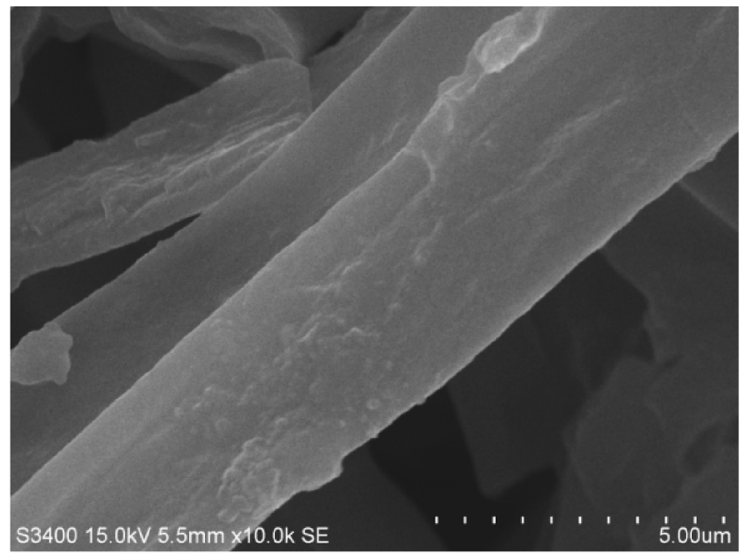

F

Fig. 9. SEM observation of ECUST-TXZ2018 before and after the adsorption of atrazine: (A) before adsorption ( $\times 700)$; (B) after adsorption ( $\times 700)$; (C) before adsorption $(\times 6.00 \mathrm{~K})$; $(\mathrm{D})$ after adsorption $(\times 6.00 \mathrm{~K})$; (E) before adsorption $(\times 10.00 \mathrm{~K})$; $(\mathrm{F})$ after adsorption $(\times 10.00 \mathrm{~K})$. 


\section{Effect of $\mathrm{NaCl}$ concentration on atrazine adsorption by} ECUST-TXZC2018

The effect of $\mathrm{NaCl}$ concentration on the adsorption rate is illustrated in Fig. 7. While increasing the $\mathrm{NaCl}$ concentration, a significant improvement in the atrazine adsorption was observed: from $72.95 \%$ in the $5 \mathrm{gL}^{-1}$ salt ion to $83.54 \%$ in the presence of an $80 \mathrm{gL}^{-1}$ salt ion. The adsorption rate of atrazine decreased to $66.42 \%$ when the salt ions concentration reached $120 \mathrm{gL}^{-1}$. These results showed that the strain was tolerant of a high concentration of salt and still had a good adsorption effect on atrazine.

\section{FTIR spectroscopy}

FTIR spectroscopy was used to analyze the changes in the surface functional groups of mycelia before and after adsorption and to evaluate their participation in the atrazine adsorption process in order to obtain information about the biosorption mechanism. The FTIR spectroscopy results before and after the adsorption of atrazine are shown in Fig. 8. The peak observed at $3272 \mathrm{~cm}^{-1}$ can be assigned to the amine $\mathrm{N}-\mathrm{H}$ and hydroxyl O-H stretching vibrations. The bands at 2920 and $2849 \mathrm{~cm}^{-1}$ correspond to asymmetric and symmetric aliphatic $\mathrm{C}-\mathrm{H}$ stretching. The peak observed at $1740 \mathrm{~cm}^{-1}$ can be attributed to the carboxylic acid or its ester. The bands at 1547 and $1654 \mathrm{~cm}^{-1}$ are the asymmetric and symmetric vibrations of ionic carboxyl groups. The bands at 1075 and $1150 \mathrm{~cm}^{-1}$ correspond to $\mathrm{C}=\mathrm{O}$ stretching vibrations. The peak at $1238 \mathrm{~cm}^{-1}$ is caused by the presence of a carboxyl group, while the peak at $1037 \mathrm{~cm}^{-1}$ indicates $\mathrm{P}-\mathrm{OH}$ stretching vibrations. ${ }^{27-31)}$

Analysis of the FTIR spectra of mycelia before and after the adsorption of atrazine showed that the intensity of these peaks had changed, and their positions had shifted. For example, the peak at $3272 \mathrm{~cm}^{-1}$ drifted obviously after atrazine adsorption, and the peak position shifted from $3272 \mathrm{~cm}^{-1}$ to $3252 \mathrm{~cm}^{-1}$; other peaks, such as those at $1740,1547,1381,1238,1150,1075$, and $1037 \mathrm{~cm}^{-1}$, drifted to $1742,1549,1375,1243,1149,1076$, and $1037 \mathrm{~cm}^{-1}$, respectively. This indicated that these functional groups might be involved in the binding of atrazine.

In addition, the adsorption of avermectin was tested in order to evaluate the strain specificity for atrazine adsorption. The FTIR spectroscopy result for avermectin is shown in the supplementary information. The peak observed at $3272 \mathrm{~cm}^{-1}$ may be attributed to amine $\mathrm{N}-\mathrm{H}$ and hydroxyl $\mathrm{O}-\mathrm{H}$ stretching vibrations. The peaks at $2920 \mathrm{~cm}^{-1}$ and $2849 \mathrm{~cm}^{-1}$ correspond to asymmetric and symmetric aliphatic $\mathrm{C}-\mathrm{H}$ stretching. The peak observed at $1740 \mathrm{~cm}^{-1}$ can be attributed to carboxylic acids or their esters. The peaks at $1547 \mathrm{~cm}^{-1}$ and $1654 \mathrm{~cm}^{-1}$ were the asymmetric and symmetric vibrations of ionic carboxyl groups. The peaks at $1075 \mathrm{~cm}^{-1}$ and $1150 \mathrm{~cm}^{-1}$ were $\mathrm{C}=\mathrm{O}$ stretching vibration. The peak at $1238 \mathrm{~cm}^{-1}$ is caused by the presence of carboxyl groups, while the peak at $1037 \mathrm{~cm}^{-1}$ represents the $\mathrm{P}-\mathrm{OH}$ stretching vibration. However, the functional groups on the mycelium surface were not changed after chlorpyrifos testing (data not shown).

There was a certain similarity between atrazine and avermectin on the adsorption-participating groups. For example, the groups corresponding to the peaks at $1740,1547,7138,1115$, 1075 , and $1037 \mathrm{~cm}^{-1}$ were involved in the adsorption of atrazine and avermectin by the strain. However, there was also a difference between the two, as $\mathrm{C}-\mathrm{H}$ of the corresponding fatty acids at 2920 and $2849 \mathrm{~cm}^{-1}$, which did not shift when adsorbing atrazine and did shift when adsorbing avermectin, indicated that the corresponding groups participated in the adsorption of avermectin and did not participate in the adsorption of atrazine.

\section{SEM characterization}

SEM images before and after the adsorption of atrazine are shown in Fig. 9. Before the adsorption of atrazine, the surface of the mycelium has granular objects. After the adsorption of atrazine, the granular objects disappear, and the surface becomes relatively smooth. Additionally, wrinkles appear on the surface of the mycelium.

As in previous reports, there are granular protuberances on the surface of some mycelia. ${ }^{33)}$ In this experiment, the mycelium chanances and conidia on the surface of Aspergillus oryzae, ${ }^{32)}$ can be observed before the adsorption, and the granules disappeared after the adsorption. Together with the results of FTIR analysis, this leads us to conclude that atrazine is adsorbed on the surface of strain ECUST-TXZC2018.

\section{Conclusion}

In this study, a strain with an atrazine adsorption function was obtained via microbial screening technology. According to the growth characteristics, a series of physical and chemical indicators, and $18 \mathrm{~S}$ rDNA results, the strain was identified as a species of Aspergillus oryzae and named ECUST-TXZC2018. The effects of different environmental conditions on the adsorption of atrazine by ECUST-TXZC2018 were explored. The optimal adsorption time was determined to be $60 \mathrm{hr}$, with the optimal adsorption occurring at a $\mathrm{pH}$ of 7 , the optimal $\mathrm{NaCl}$ concentration at $80 \mathrm{~g} \mathrm{~L}^{-1}$ and an optimal adsorption temperature of $30^{\circ} \mathrm{C}$. The results of FTIR and SEM experiments show that the hydroxyl, amine, and amide groups on the surface of mycelia are involved in the process of atrazine adsorption and cause changes in the surface morphology of the mycelia. In summary, Aspergillus oryzae ECUST-TXZC2018 has the potential to be used for comprehensive treatment of atrazine pollution in the environment.

\section{Acknowledgements}

This work was financially Sponsored by the National Key Research and Development Plan (2017YFD02003505) and the Innovation Program of Shanghai Municipal Education Commission (NO. 201701070002E00037).

\section{Conflict of interest statement}

The authors declare no conflict of interest.

\section{Electronic supplementary materials}

The online version of this article contains supplementary materials (Supplemental Figs. S1-S3), which are available at http://www.jstage.jst.go.jp/ browse/jpestics/. 


\section{References}

1) A. Shawky, R. M. Mohamed, I. A. Mkhalid, M. A. Youssef and N. S. Awwad: Visible light-responsive $\mathrm{Ag} / \mathrm{LaTiO}_{3}$ nanowire photocatalysts for efficient elimination of atrazine herbicide in water. J. Mol. Liq. 299, 112163 (2020).

2) Y. S. Al-Degs, M. I. El-Barghouthi, A. H. El-Sheikh and G. M. Walker: Effect of solution $\mathrm{pH}$, ionic strength, and temperature on adsorption behavior of reactive dyes on activated carbon. Dyes Pigm. 77, 16-23 (2008)

3) F. P. De Albuquerque, J. L. De Oliveira, V. Moschini-Carlos and L. F. Fraceto: An overview of the potential impacts of atrazine in aquatic environments: Perspectives for tailored solutions based on nanotechnology. Sci. Total Environ. 700, 134868 (2020).

4) S. Karaca, A. Gürses, M. Açıkyıldız and M. Ejder: Adsorption of cationic dye from aqueous solutions by activated carbon. Microporous Mesoporous Mater. 115, 376-382 (2008).

5) P. N. Chandra and K. Usha: Mater. Today Proc., (2020).

6) J. Xia, L. Qin, Z.-H. Du, J. Lin, X.-N. Li and J.-L. Li: Performance of a novel atrazine-induced cerebellar toxicity in quail (Coturnix C. coturnix): Activating PXR/CAR pathway responses and disrupting cytochrome P450 homeostasis. Chemosphere 171, 259-264 (2017).

7) T. E. Stoker, D. L. Guidici, S. C. Laws and R. L. Cooper: The effects of atrazine metabolites on puberty and thyroid function in the male Wistar rat. Toxicol. Sci. 67, 198-206 (2002).

8) A. B. Victor-Costa, S. M. C. Bandeira, A. G. Oliveira, G. A. B. Mahecha and C. A. Oliveira: Changes in testicular morphology and steroidogenesis in adult rats exposed to Atrazine. Reprod. Toxicol. 29, 323-331 (2010).

9) S. Jamil, P. Loganathan, J. Kandasamy, A. Listowski, J. A. Mcdonald, S. J. Khan and S. Vigneswaran: Removal of organic matter from wastewater reverse osmosis concentrate using granular activated carbon and anion exchange resin adsorbent columns in sequence. Chemosphere 261, 127549 (2020).

10) D. Jia, A. Li, C. Li, G. Liu and Y. Li: Removal atrazine using two anion-exchange resins supported nanohydrous metal-oxide particle. Chin. J. Chem. Eng. 25, 180-186 (2017).

11) H. Liu, W. Chen, C. Liu, Y. Liu and C. Dong: Magnetic mesoporous clay adsorbent: Preparation, characterization and adsorption capacity for atrazine. Microporous Mesoporous Mater. 194, 72-78 (2014).

12) P. D. Kolekar, S. M. Patil, M. V. Suryavanshi, S. S. Suryawanshi, R. V. Khandare, S. P. Govindwar and J. P. Jadhav: Microcosm study of atrazine bioremediation by indigenous microorganisms and cytotoxicity of biodegraded metabolites. J. Hazard. Mater. 374, 66-73 (2019).

13) R. Szewczyk, S. Różalska, J. Mironenka and P. Bernat: Atrazine biodegradation by mycoinsecticide Metarhizium robertsii: Insights into its amino acids and lipids profile. J. Environ. Manage. 262, 110304 (2020).

14) J. Gao, P. Song, G. Wang, J. Wang, L. Zhu and J. Wang: Responses of atrazine degradation and native bacterial community in soil to Arthrobacter sp. strain HB-5. Ecotoxicol. Environ. Saf. 159, 317-323 (2018).

15) R. Szewczyk, S. Różalska, J. Mironenka and P. Bernat: Atrazine biodegradation by mycoinsecticide Metarhizium robertsii: Insights into its amino acids and lipids profile. J. Environ. Manage. 262, 110304 (2020).

16) X. Chen, Q. Zhou, F. Liu, Q. Peng and P. Teng: Removal of nine pesticide residues from water and soil by biosorption coupled with degra- dation on biosorbent immobilized laccase. Chemosphere 233, 49-56 (2019).

17) S. Rousseaux, A. Hartmann and G. Soulas: Isolation and characterisation of new Gram-negative and Gram-positive atrazine degrading bacteria from different French soils. FEMS Microbiol. Ecol. 36, 211$222(2001)$

18) E. $\mathrm{Hu}$ and $\mathrm{H}$. Cheng: Impact of surface chemistry on microwaveinduced degradation of atrazine in mineral micropores. Environ. Sci. Technol. 47, 533-541 (2013).

19) G. Sharma, B. Thakur, A. Kumar, S. Sharma, M. Naushad and F. J. Stadler: Atrazine removal using chitin-cl-poly(acrylamide-co-itaconic acid) nanohydrogel: Isotherms and $\mathrm{pH}$ responsive nature. Carbohydr. Polym. 241, 116258 (2020).

20) Y. Zheng, B. Cheng, J. Fan, J. Yu and W. Ho: Review on nickel-based adsorption materials for Congo red. J. Hazard. Mater. 403, 123559 (2021).

21) G. Sharma, B. Thakur, A. Kumar, S. Sharma, M. Naushad and F. J. Stadler: Atrazine removal using chitin-cl-poly(acrylamide-co-itaconic acid) nanohydrogel: Isotherms and $\mathrm{pH}$ responsive nature. Carbohydr. Polym. 241, 116258 (2020).

22) J. Qu, Y. Yuan, Q. Meng, G. Zhang, F. Deng, L. Wang, Y. Tao, Z. Jiang and Y. Zhang: Simultaneously enhanced removal and stepwise recovery of atrazine and $\mathrm{Pb}$ (II) from water using $\beta$-cyclodextrin functionalized cellulose: Characterization, adsorptive performance and mechanism exploration. J. Hazard. Mater. 400, 123142 (2020).

23) X. Yang, K. Cheng and G. Jia: Molecular dynamics simulation of temperature-dependent atrazine aqueous solution. J. Mol. Liq. 256, 456-461 (2018).

24) S. Andleeb, Z. Jiang, K. U. Rehman, E. K. Olajide and Z. Ying: J. Northeast Agric. Univ. (Engl. Ed.) 23, 12-19 (2016).

25) J. P. Bell and M. Tsezos: Removal of Hazardous Organic Pollutants by Adsorption on Microbial Biomass. Water Sci. Technol. 19, 409-416 (1987).

26) R. K. Pathak and A. K. Dikshit: Effect of Various Parameters on Biosorption of Atrazine. APCBEE Procedia 1, 79-82 (2012).

27) S. Daniela, B. Alexandra, D. Mariana and M. Teodor: Biosorption of reactive dye from aqueous media using Saccharomyces cerevisiae biomass. Equilibrium and kinetic study. Open Chem. 11, 2048-2057 (2013).

28) M. R. Pouya and S. Behnam: Adsorption behavior of copper ions on alga Jania adhaerens through SEM and FTIR analyses. Sep. Sci. Technol. 52, 2062-2068 (2017).

29) N. A. Salvi and S. Chattopadhyay: Biosorption of Azo dyes by spent Rhizopus arrhizus biomass. Appl. Water Sci. 7, 3041-3054 (2017).

30) M. Torab-Mostaedi, M. Asadollahzadeh, A. Hemmati and A. Khosravi: Equilibrium, kinetic, and thermodynamic studies for biosorption of cadmium and nickel on grapefruit peel. J. Taiwan Inst. Chem. Eng. 44, 295-302 (2013).

31) Y. Yi, J. Lv, N. Zhong and G. Wu: Biosorption of $\mathrm{Cu}^{2+}$ by a novel modified spent Chrysanthemum: kinetics, isotherm and thermodynamics. J. Environ. Chem. Eng. 5, 4151-4156 (2017).

32) Z.-M. Zhang, M. Zhuang, B.-T. Wang, L. Jin and F.-J. Jin: Identification and characterization of a DevR-interacting protein in Aspergillus oryzae. Fungal Biol. 124, 155-163 (2020).

33) A. Salihi, A. Asoodeh and M. Aliabadian: Production and biochemical characterization of an alkaline protease from Aspergillus oryzae CH93. Int. J. Biol. Macromol. 94(Pt B), 827-835 (2017). 